\title{
THE COMPREHENSION AND PRODUCTION OF PLURAL FORMS OF NOUNS BY 6-YEAR-OLD AFRIKAANS-SPEAKING CHILDREN WITH AND WITHOUT SPECIFIC LANGUAGE IMPAIRMENT
}

Frenette Southwood

University of Stellenbosch

In Afrikaans, plurality is indicated phonetically in several ways. The large number of pluralisation rules and the many exceptions to these rules cause acquirers of Afrikaans to make some use of rote learning. The question arises as to how, if at all, the knowledge of pluralisation of Afrikaans-speaking children with specific language impairment (SLI) differs from that of typically developing children: if even typically developing Afrikaans-speaking children have to learn the correct phonetic realisation of the plural forms of nouns (to a certain extent) and if this learning is not yet completed by 6 years of age (Southwood, 2006), can knowledge of pluralisation then be used to differentiate between Afrikaans-speaking children with and without SLI (seeing that SLI is characterised by a deficit in grammatical morphology)? This paper attempts to answer this question by examining the comprehension and production of plural forms by 10 6-year-olds with SLI and 10 without. It was found that some selected measures of comprehension and production of pluralisation are sufficiently sensitive to differentiate between the two groups. It was also found that neither of two prominent accounts of SLI, namely the Feature Deficit Hypothesis (Gopnik, 1994a) and the Surface Hypothesis (Leonard, 1989 and others), offers an adequate explanation for the problems with pluralisation experienced by Afrikaans-speaking children.

\section{INTRODUCTION}

Specific language impairment (SLI) is a significant impairment in the spoken language ability of children in the absence of identifiable casual factors or obvious accompanying factors such as neurological deficits, mental challenges, hearing disabilities, and emotional or behavioral problems (Leonard, 1998: vi; Stark \& Tallal, 1981). Children with SLI do not form a homogeneous group (Aram, 1991: 84-85), but despite their heterogeneity, there is one characteristic that is shared by most children with SLI, namely that their language contains a lower percentage of correct use of grammatical morphemes than that of age-matched controls (cf., amongst others, Leonard, Bortolini, Caselli, McGregor \& Sabbadini, 1992; Loeb \& Leonard, 1991; Rice, Wexler \& Cleave, 1995; Ullman \& Gopnik, 1994). Children with SLI often omit grammatical morphemes from obligatory contexts and, less frequently, insert them in inappropriate contexts, as exemplified in (1) and (2) below, respectively.

(1) *two cat (cf. Oetting \& Rice, 1993)

(2) *You got a tape recorders (Gopnik, 1990a: 147), where the plural form of tape recorder is used to refer to a single tape recorder 
One linguistic account of SLI is Gopnik's (1994a) Feature Deficit Hypothesis (originally termed the Feature Blindness Hypothesis, and then revised and termed the Implicit Grammatical Rule Deficit) (Gopnik, 1990a, 1990b). On Gopnik's hypothesis, SLI is the result of a deficit in the marking of a specific class of linguistic features (which includes number, gender, person, tense, and aspect), a deficit which leads to the inability to formulate so-called implicit grammatical rules. Children acquiring English will, for example, not acquire the rule that the noun must end in an $-s$ if the noun refers to more than one of an entity.

According to Gopnik, children with SLI can compensate for the absence of these implicit rules in two ways. The first is through rote learning: These children must memorise all inflected forms, e.g. books, just as they (and typically developing children) must learn that fish, and not *fishes, is the plural form of fish. Whereas typically developing English-speaking children thus figure out, unconsciously, that $-s$ is added to the end of the noun to form the plural and therefore only have to memorise irregular plural forms (such as sheep and oxen), children with SLI have to memorise every stem (such as book) as well as every inflected form (books). The second way in which children with SLI can compensate for the absence of implicit rules, is by applying rules that were explicitly taught to them. When these children are cognitively mature enough, they can explicitly learn rules (e.g., 'add an $-s$ if there is more than one') and then apply them (Paradis \& Gopnik, 1994: 146).

According to Gopnik, this does not mean that a certain feature will always be affected if one looks at the phonological form of the utterance. Rather, there is no evidence that the phonological form of the grammatical morpheme, when it does occur, does in fact reflect the feature. The phonological form of a multimorphemic word (such as hands) may thus appear to the person with SLI to be one unanalisable unit.

As support for her hypothesis, Gopnik (1990a, 1994a, 1994b) presents the results of the study of a family that stretches over three generations. Fourteen tests were administered to the 30 family members (a grandmother, her five children and her 24 grandchildren), and samples of their spoken and written spontaneous language use were analysed. It was found that 16 of the family members (the grandmother, all three of the daughters, one of the two sons, six of the 13 granddaughters and five of the 11 grandsons) fared significantly poorer than the rest on the four tests evaluating syntactic-semantic abilities, but not on the other 10 tests. As an example, Gopnik (1990a) mentions that the two groups of family members differed significantly in their abilities to alter tense (such as when they were requested to complete the following: Every day he kisses his nanny. Yesterday he ___), and to provide the plural form of nonsense words (such as zat) (cf. also Goad \& Rebellati, 1994; Gopnik, 1994a; Ullman \& Gopnik, 1994). From the results of these studies, it appeared that the family members with SLI could not acquire implicit rules and that, where they did provide the correct surface form of a word (such as verbs in the past tense form and nouns in the plural form), they made use of forms that they had memorised.

Afrikaans is a language with limited overt grammatical morphology. For instance, grammatical gender does not exist; agreement in terms of number is not phonetically realised on verbs; and, with regard to nouns, there are no bound morphemes to indicate 'one'. Plurality, on the other hand, is indicated phonetically, but there is no default rule for forming the plural of any noun. In fact, for regular plural forms, there are many rules (up to 16) determining which suffix is the correct one (cf. Donaldson, 1993: 69-84). There are also many exceptions to these rules which have to be memorised by all speakers of Afrikaans, whether language-impaired or not. That is, speakers of Afrikaans must learn 
(i) whether the plural form is an irregular one, as in (3) to (7) below,

(3) lammers 'lambs', the plural form of lam

(4) beddens 'beds', the plural form of bed

(5) volksliedere 'national anthems', the plural form of volkslied

(6) hemde 'shirts', the plural form of hemp

(7) gerugte 'rumours', the plural form of gerug

(ii) whether the plural is formed through both suffixation and a vowel change, as in (8) and (9) below,

(8) skepe 'ships', the plural form of skip

(9) aanbiedinge 'offers', the plural from of aanbod

or (iii) whether the noun takes one of the two regular plural suffixes $-s$ or $-e$, but not the one specified by the rules for forming regular plurals, as in (10) to (11) below,

(10) tenks 'tanks', the plural form of tenk, and not tenke as expected on the analogy of kampe 'camps', the plural form of kamp

(11) ooms 'uncles', the plural form of oom, and not ome as expected on the analogy of bome 'trees', the plural form of boom

On Gopnik's hypothesis, Afrikaans-speaking children with SLI should demonstrate significant difficulty with all types of plurals, given the number of rules for pluralisation and the extent of the exceptions to these rules. This differs to what the Surface Hypothesis proposed by Leonard and his colleagues (Leonard, 1989; Leonard, Eyer, Bedore \& Grela, 1997; Leonard, McGregor \& Allen, 1992) predicts for Afrikaans. On this hypothesis, children with SLI experience problems with grammatical morphology due to the low saliency of these morphemes. The brevity and relative lack of saliency of these morphemes 'have a profound effect on the joint operations of perceiving grammatical morphemes and hypothesizing their grammatical function' (Leonard, 1998: 247). On this hypothesis, Afrikaans-speaking children with SLI should have greater difficulty with the regular $-s$ morpheme than with the regular $e$, and should fare better on irregular plural forms than on regular ones, given that the former are usually perceptually more salient than the latter.

Preliminary evidence indicated that the morpho-syntactic knowledge of even typically developing Afrikaans-speaking 6-year-olds does not yet resemble that of the adult speakers of the language (cf. Southwood, 2006). This includes their knowledge of pluralisation of nouns. The question now arises as to how, if at all, the knowledge of pluralisation of Afrikaansspeaking children with SLI differs from that of typically developing Afrikaans-speaking children. Standardised language assessment instruments often include items to test knowledge of pluralisation. But if even typically developing Afrikaans-speaking children have to consciously learn the correct phonetic realisation of plural forms (to a certain extent), and if this learning is not yet completed by 6 years of age, it is questionable whether knowledge of pluralisation can be used to differentiate between Afrikaans-speaking children with and without SLI, seeing that SLI is characterised by a deficit in grammatical morphology. This is the question addressed in the present study. 


\section{METHOLOLOGY}

\section{Participants}

Data on the comprehension and production of singular and plural forms of nouns were gathered from 20 Afrikaans-speaking children: 10 with and 10 without SLI (5 boys and 5 girls in each group). Their ages ranged from 6 years 0 months to 6 years 11 months (average 6 years 6 months for both groups). All participants were from monolingual Afrikaans-speaking homes, and exhibited normal hearing sensitivity, age-appropriate socio-emotional development and an absence of any visible neurological deficits, according to their parents and/or classroom teachers. IQ testing revealed age-appropriate intellectual development for the group with SLI. IQ testing was not performed with the typically developing group, but the parents and/or classroom teachers considered the mental development of the children in this group to be normal.

The 10 participants with SLI were identified as having language problems, diagnosed to be SLI, by qualified speech-language therapists, and received speech-language therapy at the time of this study: three at a university training hospital, one at a school for children with special needs and six from private-practicing therapists. The participants in the typically developing group had no previous referral to or treatment by a speech-language therapist, and demonstrated typical language development according to their parents and classroom teachers.

\section{Procedure}

Ten children who met the criteria for SLI were identified by their speech-language therapists as possible participants in the study. Verbal consent for the inclusion of each child in the study was obtained by the therapist, after which the researcher sent a letter to the parents to explain the aim, duration, procedure, risks, advantages, and confidentiality of the results of the study and to obtain written consent from the parents. Included with the letter was a casehistory form that the parents completed in order to provide background information on, amongst other things, the child's language development and current language abilities. After checking that no information provided on the case-history form contra-indicated inclusion in the study, a non-verbal IQ score was obtained, where such a score had not yet been obtained. If this score was 85 or above, arrangements were made to visit the child at his/her school or home. During these visits (i) assent was obtained from the child, (ii) the auditory sensitivity of the participants was screened according to the guidelines of the American Speech, Language, and Hearing Association (ASHA, 1997-2006); (iii) a language sample was collected; and (iv) language assessment tasks were performed.

Hereafter, participants for inclusion in the age-matched control group were obtained by contacting after-care centres of schools with Afrikaans as the medium of instruction. The staff were asked to identify typically developing Afrikaans-speaking 6-year-olds from monolingual Afrikaans-speaking homes. Parental consent was then obtained via the classroom teachers, and the same case-history form was completed. The age-matched controls were visited at the after-care centres. During these visits, child assent was obtained and hearing screening took place as it did for the participants in the SLI group, a language sample was collected, and the same language assessment tasks were performed. Participants were allowed to rest at any stage during the language assessment sessions and were also free to request any particular visit to end. 


\section{Language assessment tasks}

Two comprehension and one production task were performed. All three tasks took the form of researcher-participant interaction with pictures or picture sheets. The procedures were based on those used with great success with young children of different languages by researchers such as Gualmini and Crain (2002); Gualmini, Crain and Meroni (2000); Håkansson (2001); Hansson and Leonard (2003); Jakubowicz (2003); Leonard, Salameh and Hansson (2001); Marchman, Saccuman and Wulfeck (2004); and Ravid, Levie and Avivi Ben-Zvi (2003). Each task had two practice items, in order to familiarise the participants with what was required from them. All tasks were first performed with typically developing Afrikaansspeaking 3-, 4-, 5-, and 6-year-olds, during a pilot study, in order to ensure that test items were appropriate and unproblematic and that the demands placed on the participants were realistic (cf. Southwood, 2005, 2006).

To assess the comprehension of pluralisation of nouns, two types of tasks were used, namely picture selection and acceptability judgements. When the comprehension of the phonetic realisation of the grammatical feature number was assessed, participants were asked, for example, Wys vir my die sambrele 'Show me the umbrellas'. They would then have to select the correct picture. As is customary during the performance of such tasks, four-picture sheets were used (in order to elevate chance level to 0.25). For example, in the case of Wys vir my die sambrele, (i) one picture corresponded to the requested word (sambrele 'umbrellas'); (ii) one corresponded to the requested word without the plural morpheme (sambreel 'umbrella'); (iii) one was a semantically related distracter, in its plural form (reënjasse 'raincoats'); and (iv) one was a phonetically related distracter (kastele 'castles'). The syllable structure of the distracters in (iii) and (iv) was similar to that of the targeted word in (i). Only existing words were tested in this way (no nonsense words), and an equal number of plural and singular target words were tested, in order to prevent the participants from noticing that the researcher was interested in plural forms only. However, as the responses to the singular words are not relevant here, they were omitted when tallying the scores obtained on the picture selection task.

In order to determine whether participants could recognise the correct phonetic realisation of the grammatical feature number, they were required to judge whether utterances produced by the researcher were acceptable in Afrikaans. In other words, participants were asked to tell the researcher when she made a mistake. The researcher and participant looked at two-picture sheets: the first picture was that of a singular object whereas the second depicted more than one of the same object, and the researcher named the objects, e.g., Hier is een bessie, maar hier is baie bessies 'Here is one berry, but here are many berries'. Regular ( $-s$ and $-e)$ and irregular plural forms of both real and nonsense words were used correctly (e.g., foto's 'photos', plante 'plants', and knure) and incorrectly (e.g., *hoenderse 'chickens', *roks 'dresses', and *laaps) by the researcher.

The production task took the form of sentence completion. The participant was shown two pictures on one sheet of paper, given the singular form of the noun, and requested to provide the plural form of the noun. For instance, the researcher said, Hier is een venster, maar hier (pointing to a picture of more than one window) is baie ... 'Here is one window, but here are many ...'. Real words requiring regular and irregular plural suffixes were included, as were nonsense words (after Berko, 1958). 


\section{Data scoring}

Responses on the comprehension and production tasks were recorded on a score sheet. Self corrections were allowed, and only final responses were scored. Responses were placed into one of the following three categories: (i) correct response, (ii) unusable response, such as word substitutions when assessing the production of plural morphemes (e.g., the researcher saying Een skip, twee ... 'One ship, two ...' and the participant responding with bote 'boats', or Ek weet nie 'I don't know'); and (iii) incorrect response. Incorrect responses were further divided into (i) those giving insight into the aspect being assessed (for instance, the participant pointing to leeu 'lion' when asked to select the picture matching leeus 'lions'), and (ii) those not offering insight into the specific aspect being assessed (e.g., the participant pointing to luis 'louse' when asked to select the picture matching leeus).

\section{Statistical analysis}

The distribution of scores in the two groups was not expected to be normal, due to the fact that SLI samples tend to be heterogeneous and that this heterogeneity cannot be restrained if the sample is as small as it was in this study. For this reason, the (non-parametric) MannWhitney test was used to compare the two groups. Because this test calculates the average ranks assigned to the cases in the two groups, it controls for the possible disproportionately good or poor performance of individual participants. The level of significance (p-level) was taken to be 0.05 .

\section{RESULTS AND DISCUSSION}

The results are presented in table format, with scores given in the form of percentages, followed in brackets by a raw score. It will be noted that the possible maximum score for any one assessed aspect differs among the groups. This is because the following were excluded from the count of each individual participant: responses which entailed certain substitutions, such as skapies 'sheep-DIMINUTIVE-PLURAL' to the item Hier is een lam en hier is ' $n$ klomp ... 'Here is one lamb and here are many ...' and items to which a response such as Ek ken nie daardie woord nie 'I do not know that word' or Wat is dit? 'What is that?' was given.

For number comprehension, participants were required to distinguish between singular and plural and to judge the correctness of a plural form.

Table 1. Correct responses on the picture selection (comprehension) tasks

\begin{tabular}{lcccc}
\hline \multicolumn{1}{c}{ Plurals } & $\begin{array}{c}\text { Typically } \\
\text { developing } \\
\text { group }\end{array}$ & SLI group & $\begin{array}{c}\text { Significant } \\
\text { difference } \\
\text { between } \\
\text { groups? }\end{array}$ & p-level \\
\hline $\begin{array}{l}\text { Real words regular }-\mathrm{e} \\
\text { Target response }\end{array}$ & $95 \%(95 / 100)$ & $71 \%(71 / 100)$ & No & 0.126 \\
$\begin{array}{l}\text { All }- \text { e plural* } \\
\text { Real words regular }-\mathrm{s}\end{array}$ & $95 \%(95 / 100)$ & $75 \%(75 / 100)$ & No & 0.065 \\
Target response & $94 \%(93 / 99)$ & $60 \%(60 / 100)$ & Yes & 0.006 \\
All $-s$ plural* & $95 \%(94 / 99)$ & $71 \%(71 / 100)$ & Yes & 0.016 \\
\hline
\end{tabular}


*Target response as well as semantically or phonetically related distracters in plural form, for instance blare 'leaves' instead of blomme 'flowers' or varke 'pigs' instead of vurke 'forks'

As can be seen in Table 1, the average percentage of times which participants with SLI identified the plural form correctly was lower than that of the typically developing participants, but only the differences between the performance of the two groups on plurals formed with $-s$ was statistically significant. When considering the target responses as well as those entailing a semantically related item (such as seuns 'boys' instead of the target $p a$ 's 'dads') and those phonetically related ones entailing plural objects (such as teestelle 'tea sets' instead of seesterre 'star fish-PLURAL'), i.e., when comparing all plural responses given to every item, there was no significant in-group difference between the plurals formed by $-e$ and those formed by $-s$.

Table 2 contains the responses to the second type of comprehension task, viz. the judgement task. For nonsense words (such as golle, *laaps, siefaards, *foutemme and *pifs), there was no significant difference, neither between the two groups of participants nor between the plurals formed by $-e$, those formed by $-s$, and those requiring both $-e$ and voicing of the final consonant. All average scores obtained on nonsense words were at or close to chance level. On regular and irregular plural forms of real words, however, the typically developing 6-yearolds outperformed their peers with SLI, but only the difference between groups on the correct recognition of irregular plural forms of real words was statistically significant. Both groups of participants fared better on real words than on nonsense words and on the regular plural of real words than on the irregular.

Table 2. Correct responses on the judgement (comprehension) tasks

\begin{tabular}{lcccc}
\hline \multicolumn{1}{c}{ Plurals } & $\begin{array}{c}\text { Typically } \\
\text { developing } \\
\text { group }\end{array}$ & SLI group & $\begin{array}{c}\text { Significant } \\
\text { difference between } \\
\text { groups? }\end{array}$ & p-level \\
\hline Regular-e & $77 \%(46 / 60)$ & $60 \%(36 / 60)$ & No & 0.212 \\
Real words & $49 \%(103 / 209)$ & $51 \%(106 / 208)$ & No & 1.000 \\
Nonsense words & & & No & 0.098 \\
Regular $-\mathrm{s}$ & $78 \%(47 / 60)$ & $60 \%(36 / 60)$ & No & 0.444 \\
Real words & $55 \%(133 / 240)$ & $49 \%(118 / 240)$ & Yes & 0.010 \\
Nonsense words & & & No & 0.492 \\
Irregular & $62 \%(216 / 350)$ & $47 \%(165 / 348)$ & $50 \%(20 / 40)$ & \\
Real words & $50 \%(20 / 40)$ & $50 n s e n s e$ words* & &
\end{tabular}

*These were nouns which would take the regular plural suffix $-e$ but would require the voicing off the final consonant, e.g. piwwe, on the analogy of sif-siwwe 'sieve-sieves'

Participants identified more correct plural forms as being correct than they identified incorrect plural forms as being incorrect, i.e., they often tended to accept forms such as the following as correct: *twee laaps (which should be twee lape on the analogy of skape 'sheep-PLURAL' and gape 'yawns'), *twee sietele (which should be twee sietels on the analogy of bottels 'bottles' and wortels 'carrots'), and *siffe 'sieves'. It could be that these responses did not reflect their knowledge of the (un)grammaticality of plural forms but rather were due to the participant using a criterion other than (un)grammaticality to decide whether pictures have been labeled correctly. For instance, a participant could judge the researcher's utterance on whether or not he/she agrees with the name the researcher chose for the object. Possible evidence for this was sometimes seen where participants spontaneously gave a reason for their judgement, as in 
Nee, dis nie dissems nie; dis ' $n$ kamera 'No, they are not dissems; it is a camera' or Nee, dis nie lammers nie; dis skapies 'No, these are not lambs; they are sheep-PLURAL-DIMINUTIVE'. However, according to J. de Villiers (personal communication, February 2005), responses such as Nee, dis nie dissems nie; dis 'n kamera are not necessarily an indication that the participants did not understand the task. It could also be that they understood the task, thought that the utterance was ungrammatical, but did not know how to explain what was wrong with the utterance (even though they were not under any obligation to give such explanations). Upon being required to act on their as-yet undeveloped metalinguistic skills, these children offer alternative explanations for their judgements.

With regard to the production of plural forms, both groups of participants fared better with real words than with nonsense words, as shown in Table 3. Also, the two groups both had more correct responses for words pluralised by $-e$ than by $-s$, and both obtained higher scores on regular than on irregular plural forms. The statistically significant differences between the groups were for $-s$ plurals of nonsense words and for the irregular plural form of nonsense and real words.

Table 3. Correct responses on the sentence completion (production) tasks

\begin{tabular}{|c|c|c|c|c|}
\hline Plurals & $\begin{array}{c}\text { Typically } \\
\text { developing } \\
\text { Group }\end{array}$ & SLI group & $\begin{array}{c}\text { Significant } \\
\text { difference } \\
\text { between } \\
\text { groups? }\end{array}$ & p-level \\
\hline \multicolumn{5}{|l|}{ Regular-e } \\
\hline Real words & $83 \%(81 / 98)$ & $80 \%(78 / 97)$ & No & 0.784 \\
\hline Nonsense words & $47 \%(93 / 199)$ & $17 \%(33 / 200)$ & No & 0.073 \\
\hline \multicolumn{5}{|l|}{ Regular $-\mathrm{s}$} \\
\hline Real words & $61 \%(59 / 97)$ & $62 \%(61 / 98)$ & No & 0.873 \\
\hline $\begin{array}{l}\text { Nonsense words } \\
\text { Irregular }\end{array}$ & $58 \%(140 / 240)$ & $24 \%(57 / 240)$ & Yes & 0.030 \\
\hline Real words & $36 \%(108 / 300)$ & $20 \%(56 / 286)$ & Yes & 0.023 \\
\hline Nonsense words* & $18 \%(7 / 40)$ & $0 \%(0 / 40)$ & Yes & 0.030 \\
\hline
\end{tabular}

*These were nouns which would take the regular plural suffix $-e$ but would require the voicing off the final consonant, e.g. lif-liwwe, on the analogy of sif-siwwe 'sieve-sieves'

Although, theoretically, there exists a difference between the two groups for the formation of irregular plurals, in practice performance on the production of irregular plural forms is not likely to be used to differentiate between the two groups. The reasons for this are two-fold. Firstly, the irregular form of nonsense words can be tested in only a very limited manner: only singular words with a word-final [f] (such as saf, of which the plural would be sawwe) and with a word-final [rx] (such as [lærx] of which the plural would be [lærgə]) can be used. Secondly, both groups fared very poorly on the irregular plural form, whether of real or of nonsense words; the group with SLI merely fared statistically significantly worse than the typically developing group. When comparing groups in real-life assessment situations, one aims to make use of measures where at least one of the groups performs satisfactorily, otherwise questions are raised about the validity of the measures. This means that, despite the statistically significant difference between the two groups in terms of the formation of irregular plural forms, it is unlikely that this measure will be used for assessment purposes by speech-language therapist and teachers. 


\section{CONCLUSION}

The aim of this paper was to answer the question which can be paraphrased as follows: Given the large number of exceptions to the large number of pluralisation rules and given the fact that the knowledge of pluralisation of typically developing Afrikaans-speaking children is not yet fully developed by the age of 6 years, can knowledge of pluralisation be used to differentiate between Afrikaans-speaking children with and without SLI?

In order to answer this question, two comprehension tasks and one production task were administered to typically developing Afrikaans-speaking 6-year-olds and to their peers with SLI. The children with SLI fared worse than their non-impaired peers on the comprehension of regular $-s$ plural forms of real words and irregular plural forms of nonsense words, as well as on the production of the irregular plural form of both real and nonsense words and of the regular $-s$ plural form of nonsense words.

On Gopnik's Feature Deficit Hypothesis, Afrikaans-speaking children with SLI should demonstrate problems with the consistent grammatical use of the singular vs. plural forms of nouns, given that these children have to memorise the plural form of each noun. This prediction is only partly borne out by the results of this study, in the sense that the irregular plural form of real words is produced with greater accuracy by the typically developing children than by their peers with SLI (cf. Table 1). Also, the children with SLI fare worse than their typically developing peers on the production of the plural forms of nonsense words (irregular forms and regular $-s$ forms), i.e., on words which could not have been memorised as they have never been heard before (cf. Table 1). However, the fact that the plural form of nonsense words is comprehended equally well (or rather equally poorly) by Afrikaansspeaking children with and without SLI (cf. Table 2), begs explanation. Also, one would expect the typically developing children to fare better than they did on the task involving the comprehension and production of plural forms of nonsense words (i.e., one would expect a smaller difference between their scores on the tasks involving real words and those involving nonsense words), as the typically developing children should be able to apply the pluralisation rules successfully to previously unheard nouns as well (cf. Tables 2 and 3).

The predictions of the Surface Hypothesis were also partly borne out by the findings of this study: If one considers all plural responses on the picture selection task, the scores for pluralisation by $-e$ and by $-s$ are comparable (cf. Table 1). Because [s] is perceptually less salient than [ə], one would have expected the children to fare significantly better on the $-e$ plural forms than on the $-s$. In terms of production, children with SLI fare better with $-e$ than with $-s$ (but so do typically developing children) and worse with the perceptually more salient irregular plural forms (cf. Table 3).

It appears then that neither of the two accounts discussed here offers an adequate explanation for the problems with pluralisation experienced by Afrikaans-speaking children. The results of this study added confirmation to a previous finding that the morpho-syntactic abilities of even typically developing Afrikaans-speaking 6-year-olds do not yet resemble those of adult speakers of the language. Even so, some selected measures of comprehension and production of pluralisation are sensitive enough to differentiate Afrikaans-speaking 6-year-olds with SLI from those with typical language development. 


\section{ACKNOWLEDGEMENT}

This material is based on work financially supported by The National Research Foundation. Any opinion, findings, conclusions or recommendations expressed in this material are those of the author and therefore the NRF does not accept any liability in regard thereto.

\section{REFERENCES}

ARAM, DM. 1991. Comments on specific language impairment as a clinical category. Language, Speech, and Hearing Services in Schools, 22:84-87.

AMERICAN SPEECH AND HEARING ASSOCIATION. 1997-2006. Hearing screening. Available online at http://www.asha.org/public/hearing/testing/

BERKO, J. 1958. The child's learning of English morphology. Word, 14:150-177.

DONALDSON, BC. 1993. A grammar of Afrikaans. Berlin: Mouton de Gruyter.

GOAD, H \& C REBELLATI. 1994. Pluralization in specific language impairment: Affixation or compounding? McGill Working Papers in Linguistics, 10:24-40.

GOPNIK, M. 1990a. Feature-blind grammar and dysphasia. Nature, 344:715.

GOPNIK, M. 1990b. Feature blindness: a case study. Language Acquisition, 1(2):139-164.

GOPNIK, M. 1994a. Impairments of syntactic tense in a familial language disorder. McGill Working Papers in Linguistics, 10(1/2):67-80.

GOPNIK, M. 1994b. The family. McGill Working Papers in Linguistics, 10:1-4.

GUALMINI, A \& S CRAIN. 2002. Why no child or adult must learn De Morgan's laws. In Proceedings of the $26^{\text {th }}$ Boston University Conference on Language Development. Somerville, MA: Cascadilla Press, 243-254.

GUALMINI, A, S CRAIN \& L MERONI. 2000. Acquisition of disjunction in conditional sentences. In Proceedings of the $24^{\text {th }}$ Boston University Conference on Language Development. Sommerville, MA: Cascadilla Press, 367-378.

HÅKANSSON, G. 2001. Tense morphology and verb-second in Swedish L1 children, L2 children and children with SLI. Bilingualism: Language and Cognition, 4:85-99.

HANSSON, K \& LB LEONARD. 2003. The use and productivity of verb morphology in specific language impairment: An examination of Swedish. Linguistics, 41:351-379.

JAKUBOWICZ, C. 2003. Computational complexity and the acquisition of functional categories by French-speaking children with SLI. Linguistics, 41(2):175-211.

LEONARD, L. 1989. Language learnability and specific language impairment. Applied Psycholinguistics, 10:179-202.

LEONARD, LB. 1998. Children with specific language impairment. Cambridge, USA and London: MIT Press. 
LEONARD, LB, U BORTOLINI, MC CASELLI, KK MCGREGOR \& L SABBADINI. 1992. Morphological deficits in children with specific language impairment: The status of features in the underlying grammar. Language Acquisition, 2(2):151-179.

LEONARD, LB, JA EYER, LM BEDORE \& BG GRELA. 1997. Three accounts of the grammatical morpheme difficulties of English-speaking children with specific language impairments. Journal of Speech, Language and Hearing Research, 40:741-753.

LEONARD, LB, K MCGREGOR \& G ALLEN. 1992. Grammatical morphology and speech perception in children with specific language impairment. Journal of Speech and Hearing Research, 35:1076-85.

LEONARD, LB, E-K SALAMEH \& K HANSSON. 2001. Noun phrase morphology in Swedishspeaking children with specific language impairment. Applied Psycholinguistics, 22(4):619639.

LOEB, DF \& LB LEONARD. 1991. Subject case marking and verb morphology in normally developing and specifically language-impaired children. Journal of Speech and Hearing Research, 34:340-346.

MARCHMAN, VA, C SACCUMAN \& B WULFECK. 2004. Productive use of the English past tense in children with focal brain injury and specific language impairment. Brain and Language, $88: 202-214$

OETTING, JB \& ML RICE. 1993. Plural acquisition in children with specific language impairment. Journal of Speech and Hearing Research, 36:1236-1248.

PARADIS, M \& M GOPNIK. 1994. Compensatory strategies in familial language impairment. McGill Working Papers in Linguistics, 10(1/2):142-149.

RAVID, D, R LEVIE \& GA BEN-ZVI. 2003. The role of language typology in linguistic development: Implications for the study of language disorders. In Levy Y \& J Schaeffer (eds), Language competence across populations. Toward a definition of specific language impairment. Mahwah: Lawrence Erlbaum Associates, 171-193.

RICE, M, K WEXLER \& P CLEAVE. 1995. Specific language impairment as a period of extended optional infinitive. Journal of Speech and Hearing Research, 38:850-863.

STARK, RE \& P TALLAL. 1981. Selection of children with specific language deficits. Journal of Speech and Hearing Disorders, 46:114-122.

ULLMANN, M \& M GOPNIK. 1994. The production of inflectional morphology in hereditary specific language impairment. McGill Working Papers in Linguistics, 10(1/2):81-118.

\section{BIOGRAPHIC NOTE}

Frenette Southwood is a lecturer in the Department of General Linguistics at Stellenbosch University. She has a strong interest in developmental language disorders and second language acquisition. 